\title{
Autonomic neuropathy in an alcoholic population
}

\author{
Fiona Barter and Andrew R. Tanner ${ }^{1}$ \\ Department of Medicine II, Southampton General Hospital, Southampton and 'North Tees General Hospital, \\ Hardwick Estate, Stockton-on-Tees, Cleveland, UK.
}

\begin{abstract}
Summary: Autonomic nervous system integrity has been assessed in 30 alcoholic subjects and 30 agesex matched controls using five simple tests of cardiovascular responses. There was evidence of parasympathetic neuropathy alone in five of the alcoholic subjects (16\%) and of combined parasympathetic and sympathetic neuropathy in an additional six (20\%). None of the controls showed any abnormality. Within the alcoholic group, those with autonomic neuropathy were older, were more likely to be female and to have established alcoholic liver disease. Symptoms were a poor guide to the presence or absence of autonomic neuropathy.
\end{abstract}

\section{Introduction}

Peripheral neuropathy is a common finding in an alcoholic population but there is only limited information concerning autonomic neuropathy in these subjects. In one recent survey ${ }^{1}$ twenty chronic alcoholics, selected on the basis of having peripheral neuropathy, were studied and shown to have a high prevalence of autonomic neuropathy. Previous postmortem studies have established the presence of vagal nerve degeneration in chronic alcoholics. ${ }^{2}$ Melgaard \& Somnier ${ }^{3}$ investigated cardiac neuropathy in 14 chronic alcoholics by measuring beat-to-beat variation. They found significantly increased variation in this group, reflecting impaired neurogenic control of the heart. A more recent study ${ }^{4}$ has shown an incidence of vagal neuropathy of $64 \%$ in patients with established alcoholic cirrhosis. These studies were on carefully selected groups of subjects. The aims of the present study were to assess autonomic nervous system function in an unselected group of alcoholic subjects using five simple tests of cardiovascular responses.

\section{Subjects and methods}

Thirty consecutive subjects aged 24-73 years (median 50 years) attending hospital out-patient departments, were studied. Fourteen of these subjects had alcoholic liver disease and 16 of the subjects were identified as having an alcohol dependence problem through the psychiatric services. All had an average alcohol intake of more than $80 \mathrm{~g} /$ day (range $80-900 \mathrm{~g} /$ day, median

Correspondence: $\quad$ A.R. $\quad$ Tanner, $\quad$ M.A., $\quad$ M.R.C.P., F.R.A.C.P., D.M

Accepted: 16 June 1987
$400 \mathrm{~g} /$ day) and had been drinking heavily for many years (mean 24 years). At the time of testing all had abstained from alcohol for more than 5 days.

Thirty age and sex matched controls attending for routine upper gastrointestinal endoscopy were also studied. All had an average alcohol intake of less than $50 \mathrm{~g} /$ day (range $0-50 \mathrm{~g} /$ day, median $7 \mathrm{~g} /$ day). As independent control groups, 14 normal hospital staff and 8 subjects with non-alcoholic liver disease were also studied.

Any subjects with a history of heart disease or diabetes mellitus, or who were taking medication likely to influence the interpretation of the autonomic function tests, such as diuretics or $\beta$-blockers, were excluded from the study. The study protocol was approved by the local ethical committee (study 547:84).

\section{Clinical assessment}

A careful assessment of the pattern and quantity of alcohol intake was made by questionnaire. Subjects were asked about symptoms of peripheral neuropathy and a full clinical neurological examination was made. Symptoms of autonomic neuropathy were also assessed by asking about postural symptoms, diarrhoea (especially nocturnal), stomach bloating, gustatory sweating, impotence and difficulty with micturition.

\section{Autonomic function tests}

The five tests of cardiovascular responses employed were: (a) heart rate response to Valsalva's manoeuvre; (b) heart rate response to deep breathing; (c) immediate heart rate response to standing $(30: 15$ ratio); (d) blood pressure response to standing; (e) 
Table I Reference values for cardiovascular autonomic function. ${ }^{5}$

\begin{tabular}{lccc}
\hline & Normal & Borderline & Abnormal \\
\hline $\begin{array}{l}\text { 1. Heart rate response to Valsalva's } \\
\text { manoeuvre, Valsalva ratio. }\end{array}$ & $>1.21$ & $1.11-1.20$ & $<1.10$ \\
$\begin{array}{l}\text { 2. Heart rate variation (R-R interval) } \\
\text { during deep breathing, beats/min }\end{array}$ & $>15$ & $11-14$ & $<11$ \\
$\begin{array}{l}\text { 3. Immediate heart rate response to } \\
\text { standing, 30:15 ratio }\end{array}$ & $>1.04$ & $1.01-1.03$ & $<1.00$ \\
$\begin{array}{l}\text { 4. Blood pressure response to stand- } \\
\text { ing (fall in systolic blood pressure, } \\
\text { mm Hg) }\end{array}$ & $<10$ & $11-29$ & $>30$ \\
$\begin{array}{l}\text { 5. Blood pressure response to sus- } \\
\text { tained handgrip (increase in diastolic } \\
\text { pressure, mm Hg) }\end{array}$ & $>16$ & $11-15$ & $<11$ \\
\hline
\end{tabular}

blood pressure response to sustained handgrip.

Tests $\mathrm{a}, \mathrm{b}$ and $\mathrm{c}$ assess parasympathetic function; $\mathrm{d}$ and e, sympathetic function. The tests were performed according to Ewing \& Clarke. ${ }^{5}$ Only definitely abnormal results (using the criteria of Ewing \& Clarke) were classed as abnormal. Results within the borderline range of Ewing and Clarke were regarded as normal. Those subjects with only a single abnormal result were classified as not having established autonomic neuropathy; if two or more results were abnormal subjects were classified as having a parasympathetic neuropathy or a combined autonomic neuropathy. No subject had abnormalities of sympathetic function alone. The reference values of Ewing and Clarke are shown in Table I. A brief comparison between alcoholics and controls is shown in Table II.

\section{Statistics}

Results between the two groups were compared directly using a standard $t$-test or Mann-Whitney test as appropriate. Chi-square test with Fisher's correc-

Table II Comparison of alcoholic and control groups

\begin{tabular}{|c|c|c|}
\hline & $\begin{array}{c}\text { Controls } \\
n=30\end{array}$ & $\begin{array}{c}\text { Alcoholics } \\
n=30\end{array}$ \\
\hline $\begin{array}{l}\text { Mean age (years) } \\
\text { Median alcohol intake (g/day) } \\
\text { Mean duration of alcohol intake } \\
\text { (years) } \\
\text { Clinical evidence of peripheral } \\
\text { neuropathy } \\
\text { Symptoms of autonomic } \\
\text { neuropathy }\end{array}$ & $\begin{array}{l}51.5 \\
7 \\
23 \\
0 \\
10(33 \%)\end{array}$ & $\begin{array}{l}50.3 \\
400 \\
24 \\
19(64 \%) \\
16(53 \%)\end{array}$ \\
\hline
\end{tabular}

tion was used to analyse the differences within the alcoholic group and between alcoholics and controls.

\section{Results}

There was a significantly lower value for the mean heart rate response to the Valsalva's manoeuvre in the alcoholic group compared to controls (Valsalva ratio 1.4 versus $1.65 ; P<0.01)$. Six alcoholic subjects had a definitely abnormal response $(<1.1)$ as compared to none of the controls. The mean value for heart rate variation during deep breathing was not different between alcoholics and controls but ten alcoholics had a definitely abnormal value ( $<10$ beats/min) compared to four controls. There was a significant difference between alcoholics and controls for the mean heart rate response to standing (30:15 ratio; alcoholics 1.03 , controls $1.13 ; P<0.001)$ with ten alcoholics showing a definitely abnormal value $(<1.0)$ compared to three controls.

The mean postural drop in systolic blood pressure on standing was $9 \mathrm{~mm} \mathrm{Hg}$ for the control group $(P<0.05)$. A postural drop of more than $30 \mathrm{~mm} \mathrm{Hg}$ was considered definitely abnormal and occurred in only two alcoholics and none of the controls. The mean rise in diastolic blood pressure on sustained handgrip was $20.2 \mathrm{~mm} \mathrm{Hg}$ in the controls, compared to $16.7 \mathrm{~mm} \mathrm{Hg}$ in the alcoholics $(P<0.05)$. Eight of the alcoholics had definitely abnormal values $(<10 \mathrm{~mm} \mathrm{Hg}$ ) compared to none of the controls.

The heart rate response to standing was the most sensitive test (82\%) with high specificity. Heart rate response to Valsalva's manoeuvre and postural drop in blood pressure were highly specific but of low sensitivity. The results in hospital staff did not differ significantly from controls. The eight subjects with non-alcoholic liver disease did not differ significantly from controls but were significantly different 
Table III Autonomic abnormalities in the various groups

\begin{tabular}{lcccc}
\hline $\begin{array}{l}\text { Classification of } \\
\text { autonomic damage }\end{array}$ & $\begin{array}{c}\text { Alcoholics } \\
n=30\end{array}$ & $\begin{array}{c}\text { Controls } \\
n=30\end{array}$ & $\begin{array}{c}\text { NALD* } \\
n=8\end{array}$ & $\begin{array}{c}\text { Staff } \\
n=14\end{array}$ \\
\hline $\begin{array}{c}\text { No abnormal tests } \\
\text { Single abnormal test }\end{array}$ & 13 & 24 & 5 & 13 \\
1 & 6 & 2 & 0 \\
Parasympathetic damage & $5(16 \%)$ & 0 & 1 & 0 \\
$\begin{array}{l}\text { Combined parasympathetic and sym- } \\
\text { pathetic damage }\end{array}$ & $6(20 \%)^{* *}$ & 0 & 0 \\
\hline
\end{tabular}

*NALD- non alcoholic liver disease

**These subjects are in addition to those with parasympathetic damage alone; thus $36 \%$ of alcoholic subjects had evidence of autonomic neuropathy.

$(P=0.02)$ from the alcoholic group using the most sensitive test, heart rate response to standing. These results are summarized in Table III.

Within the alcoholic group 11 subjects had autonomic neuropathy and, when compared to the 19 without autonomic neuropathy were significantly older and were more likely to have established alcoholic cirrhosis and peripheral neuropathy. These results are summarized in Table IV. Four of the five alcoholic women had autonomic neuropathy compared to seven of 25 men $(P=0.004)$. There was no significant correlation between symptoms of autonomic neuropathy and objective signs. The resting pulse rate was a poor guide to the presence or absence of autonomic neuropathy (controls $75 \pm 5$ beats $/ \mathrm{min}$; alcoholics without autonomic neuropathy $83 \pm 8$ beats/min; alcoholics with autonomic neuropathy $76 \pm 8$ beats $/ \mathrm{min})$.

\section{Discussion}

Autonomic neuropathy was a frequent finding in our alcoholic group. It is possible that some of the documented abnormalities reflect an underlying alcoholic cardiomyopathy but none of the subjects studied had clinically detectable heart disease. The disease group under study was an alcoholic population with a very high consistent alcohol intake which had led to medical or psychiatric problems. These results should not, therefore, be extrapolated to a general alcoholic population. Nevertheless, this study emphasizes that one third of alcoholics presenting to a hospital department are likely to have an established autonomic neuropathy. Prospective studies will be necessary to establish whether this has any prognostic significance but experience with a diabetic population would suggest that sudden death can be expected more frequently in those with autonomic neuropathy. ${ }^{6}$

Symptoms for autonomic neuropathy are very nonspecific and it is not surprising that they were a poor guide to the presence or absence of neuropathy. In the control group a large number of patients $(33 \%)$ complained of bloating, reflecting their attendance for routine gastroscopy. From the present study we conclude that a combination of heart rate response to Valsalva's manoeuvre, heart rate response to standing and postural drop in blood pressure are the most appropriate screening tests. The other two tests did not increase diagnostic efficiency. We found very poor compliance with deep breathing and with maintaining a sustained handgrip in the alcoholic group and this

Table IV Comparisons within the alcoholic group between those with and those without autonomic neuropathy.

\begin{tabular}{lcll}
\hline & $\begin{array}{c}\text { Alcoholics with } \\
\text { autonomic neuropathy } \\
n=11\end{array}$ & $\begin{array}{c}\text { Alcoholics without } \\
\text { autonomic neuropathy } \\
n=19\end{array}$ \\
\hline Age (years) & 57 & 46 & $P<0.05$ \\
Alcohol intake (g/day) & 220 & 340 & NS \\
Duration of intake (years) & 28 & 22 & NS \\
Alcoholic liver disease & $9(82 \%)$ & $5(26 \%)$ & $P<0.001$ \\
Clinical peripheral neuropathy & $10(91 \%)$ & $9(47 \%)$ & $P<0.05$ \\
Autonomic symptoms & $4(36 \%)$ & $12(63 \%)$ & NS \\
\hline
\end{tabular}


may have contributed to the poor discriminatory capacity of these tests. We have used a very rigid definition for an abnormal postural diastolic blood pressure drop. A change in threshold would increase sensitivity with no change in specificity.

In conclusion, autonomic neuropathy is a common finding in alcoholics presenting to hospital. This is associated with established liver disease, peripheral neuropathy and female sex. As in a diabetic popula-

\section{References}

1. Duncan, G., Johnson, R.H.. Lambie, D.G. \& Whiteside, E.A. Evidence of vagal neuropathy in chronic alcoholism. Lancet 1980, ii: 1053-1057.

2. Novak, D.J. \& Victor, M. The vagus and sympathetic nerves in alcoholic neuropathy. Arch Neurol 1974, 30: 273-284.

3. Melgaard, B. \& Somnier, F. Cardiac neuropathy in chronic alcoholics. Clin Neurol Neurosurg 1981, 83: 219224. tion, this finding may have important prognostic significance, but further studies are necessary.

\section{Acknowledgements}

We should like to thank the staff on the endoscopy unit at Southampton General Hospital for their help with this study, and Ms Lynn Johnson for preparing the manuscript.

4. Decaux, G., Cauchie, P., Soupart, A., Kruger, M. \& Delwiche, $F$. Role of vagal neuropathy in the hyponatraemia of alcoholic cirrhosis. Br Med J 1986, 293: 1534-1537.

5. Ewing, D.J. \& Clarke, B.F. Diagnosis and management of diabetic autonomic neuropathy. Br Med J 1982, 285: 916919.

6. Ewing, D.J., Campbell, I.V. \& Clarke, B.F. The natural history of diabetic autonomic neuropathy. $Q J \mathrm{~J}$ Med 1980 , 49: $95-108$. 